ISSN: 0514-7336

DOI: http://dx.doi.org/10.14201/zephyrus201983165183

\title{
RECURSOS Y HÁBITOS DE CONSUMO DE LA CABAÑA GANADERA EN CARTHAGO SPARTARIA EN ÉPOCA BIZANTINA
}

\section{Resources and consumption patterns of livestock in Carthago Spartaria during the Byzantine age}

\author{
Juan E. Padilla Sánchez*, Arturo Morales Muñiz** y Sebastián F. Ramallo Asensio* \\ * Dpto. de Prehistoria, Arqueología, H. a Antigua, H. a Medieval y CC y TT Historiográficas. Facultad de Letras-UMU. \\ C/ Santo Cristo, 1. 30001 Murcia. Correo-e: juanenrique.padilla@um.es; sfra@um.es. ID ORCID: 0000-0003- \\ 1828-3996 \\ ** Laboratorio de Arqueozoología. Facultad de Ciencias-UAM. C/ Francisco Tomás y Valiente, 7. 28049 Madrid. \\ Correo-e: arturo.morales@uam.es.ID ORCID:0000-0002-9933-6836
}

Recepción: 1/10/2018; Revisión: 22/02/2019; Aceptación: 15/03/2019

Resumen: Este trabajo presenta los resultados del análisis arqueofaunístico del material óseo del barrio portuario de época bizantina superpuesto al teatro romano de Carthago Spartaria (Cartagena, Murcia). Sobre una amplia muestra de 2.723 piezas, procedentes de pozos de desecho y basureros, se determinan las estrategias productivas y los patrones de consumo de la cabaña ganadera de una fase histórica de la ciudad cuya fisonomía ya nada tiene que ver con la imagen monumental de la urbe romana. Se ha determinado el uso de una ganadería mixta, con un predominio de ovicaprinos y bovinos frente a una escasa presencia de suidos y équidos, así como de fauna cinegética. La mayoría de los animales, a excepción de las cabras y los cerdos, así como ciertos bovinos, fueron sacrificados en edad plenamente adulta, lo que implica que se aprovecharon tanto sus productos secundarios como su fuerza tractora. La ganadería se confirma como una importante actividad económica, en un momento en que la explotación agrícola del entorno sufre una considerable reducción a juzgar por la desaparición de la mayor parte de los establecimientos rurales de las décadas precedentes. La cabańa representada y las condiciones de cría y mantenimiento contribuyen a proporcionar una imagen "ruralizada" de la vieja capital hispana.

Palabras clave: arqueofauna; basurero; dieta; teatro romano; Cartagena.

AвSTRACT: This work presents the results from the analysis of the bone material from the Byzantine harbor quarter overlapping the Roman theater of Carthago Spartaria (Cartagena, Murcia). From a broad sample of 2,723 fragments from debris pits and garbage dumps, the production strategies and the consuming patterns of the livestock are established during a historical period of the city in which its appearance has nothing to do with the monumental image of a Roman town. The use of mixed farming is established, with a predominance of caprine and bovine versus a scant presence of suids and equines, as well as wild hunted fauna. Most of the animals, with the exception of goats and pigs, as well as certain bovines, were sacrificed in full adulthood. This implies that both their secondary products and their draft force were used. Livestock managing is confirmed as an important economic activity, at a moment when agricultural exploitation of the environment undergoes substantial diminishing as judged from the disappearance of the vast majority of rural sites from preceding decades. The represented livestock and the herding and maintenance conditions contribute to provide a "rural-like" image of the old Hispanic capital.

Key words: Archeofauna; garbage dumps; diet; Roman theater; Cartagena. 


\section{Introducción}

En las dos últimas décadas se han publicado varios estudios arqueozoológicos del mundo tardorromano y la Alta Edad Media para la Península Ibérica (Vigil-Escalera et al., 2014; Grau, 2014, 2009; Estrada y Nadal, 2007), en línea con lo que se ha venido haciendo en Europa (Van Ossel, 2010; Peytremann, 2003; Arthur, 1994) y en el norte de África (Burke, 2001; Nobis, 1999). Pese a todos estos estudios, referidos sobre todo a aldeas y pequeños poblados, se tiene poca información de auténticas entidades urbanas de este complejo período.

A esto hay que añadir que los estudios, que se han centrado en la reconstrucción de la dieta y economía ganadera para época paleobizantina, muestran un sesgo geográfico importante, dejando sistemáticamente de lado al Mediterráneo occidental y, por ende, a la Península Ibérica. Un ejemplo lo tenemos en el trabajo de Kroll $(2012,2010)$ donde hace una revisión de todos los yacimientos con material faunístico del Imperio Bizantino, con una recopilación de 47 yacimientos concentrados en regiones del Mediterráneo oriental, siendo Italia y Cartago el límite occidental para el análisis.

En este contexto, el objetivo de este trabajo ${ }^{1}$ es analizar mediante un análisis faunístico las estrategias productivas y los patrones de uso y consumo de la cabaña ganadera en una localidad de la importancia de Carthago Spartaria (Cartagena), una ciudad con un poblamiento continuado desde su fundación hacia el 228 a. C., que desempeña a finales de la Antigüedad un papel capitalizador de los dominios bizantinos en la Península Ibérica en el marco de la restitutio Imperii impulsada por Justiniano. A ello se añade su carácter de puerto de primer orden dentro del Mediterráneo, eje vertebrador de todo el comercio regional y escala intermedia en las rutas de

1 Este trabajo se ha realizado en el marco del Proyecto de Investigación, Carthago Nova desde su entorno litoral. Paleotopografía y evolución medioambiental del sector central del sureste ibérico. Dinámica poblacional y productiva (HAR201785726-c2-1-P), del Ministerio de Economía y Competitividad, Agencia Estatal de Investigación, parcialmente financiado con Fondos FEDER. navegación hacía el mediodía peninsular y la costa africana.

Los resultados aportan nuevos argumentos para el debate en torno a la economía y sociedad de un espacio de tales características, en el arco cronológico entre el final de la Antigüedad y la época paleoandalusí (Crabtree, 2010; McCormick, 2003, 2001); sobre todo en referencia a continuidades o cambios respecto al mundo romano, a la comparación del modelo productivo de una urbe con el de una aldea y, por último, a la relación en los patrones de subsistencia con el mundo bizantino del $\mathrm{N}$ de África.

\section{El yacimiento de Carthago Spartaria: el contexto arqueológico}

Hacia el 228 a. C. el general cartaginés Asdrúbal funda la ciudad de Qart Hadasth en el sureste de la Península Ibérica. Geógrafos e historiadores antiguos recalcan su singular orografía, las excelentes condiciones de su puerto y su proximidad a ricos afloramientos metalíferos. Tras la conquista romana se la renombra Carthago Nova, topónimo que alterna en las fuentes clásicas con el de Carthago Spartaria, con el que la cita san Isidoro a comienzos del s. vil d. C. La ciudad púnico-romana se levanta sobre un promontorio, al fondo de una abrigada bahía y entre cinco colinas de altura y superficie desigual. Por el norte una amplia zona pantanosa impide la expansión urbana. Al o, una zona bien protegida albergó las áreas portuarias y de fondeo. Precisamente, a partir del s. Iv, el núcleo habitado se concentró en la mitad occidental de la ciudad más antigua y próxima al puerto, mientras que gran parte de la otra mitad fue ocupada por una necrópolis que alcanzará una notable expansión entre los ss. VI y principios del vis, período en gran parte protagonizado por el control de la ciudad por las tropas de Justiniano (c. 555-625). Ese proceso de repliegue continuó durante los siglos posteriores, concentrándose la población en la ladera suroccidental del Cerro de la Concepción, hasta que la conquista cristiana a mediados del s. XIII impulsó 


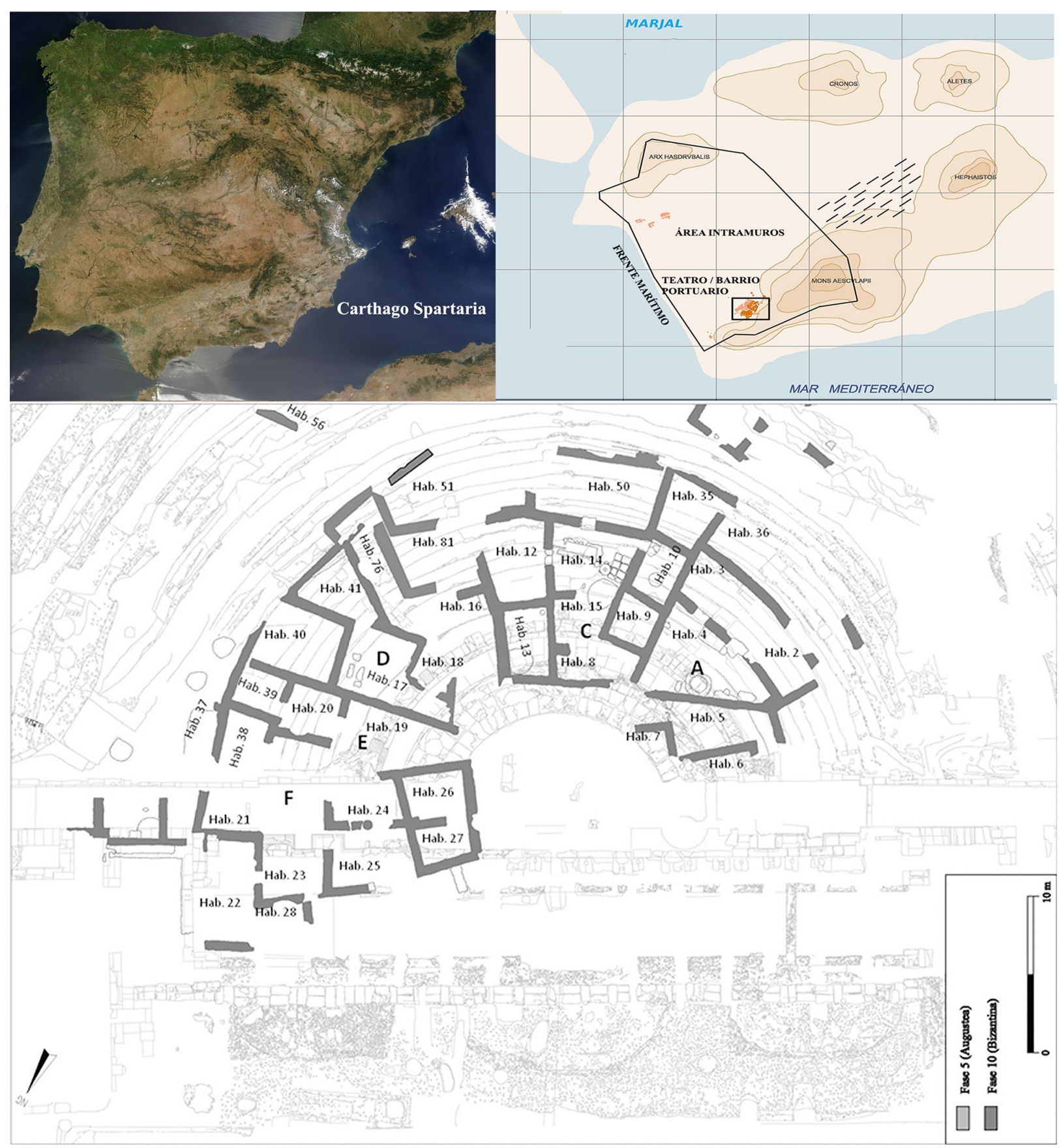

FIG. 1. Localización de Carthago Spartaria y del barrio bizantino sobre la estructura desmantelada del teatro romano (Archivo: Univ. de Murcia/Museo del Teatro Romano de Cartagena).

de nuevo una lenta expansión de la trama urbana que, no obstante, no volverá a alcanzar los límites de la ciudad romana hasta el s. XviII (Ramallo et al., 2013).
Los restos óseos estudiados proceden de un barrio portuario de época bizantina -mediados del s. VI-primer tercio del s. viI- construido sobre las estructuras desmanteladas del teatro de época augústea 
(Fig. 1). Previamente, los muros del edificio de espectáculos habían sido parcialmente reutilizados por un edificio de carácter comercial -un almacén público o mercado-, construido a mediados del s. v, que ocupó la mayor parte del cuerpo escénico, orchestra y gradas inferiores de la ima cavea, empleando en sus cimientos gran parte del material arquitectónico de la monumental scaenae frons. Las estructuras se distribuyen de forma escalonada por la pendiente del Cerro de la Concepción, en parte superpuestas a la media e ima cavea del teatro, cuyas gradas son recortadas o parcialmente colmatadas para nivelar los pavimentos de las estancias; en la parte baja, los muros se encajan entre las estructuras arruinadas del propio teatro. El paso entre ambos sectores se realiza mediante profundas cimentaciones que sirven para aterrazar los espacios ascendentes hacia la cavea. Las estancias superiores se sustentan mediante muros maestros, radiales al arco de la orchestra, a los que se adosan o traban otros perpendiculares -o levemente arqueados-, formando espacios de planta trapezoidal, rectangular, cuadrangular e incluso triangular. Patios centrales, abiertos a las calles, permiten articular las distintas unidades domésticas formadas por 2, 3 o 4 compartimentos. En los patios se ubican hornos, rebancos o piletas. Los muros se levantan mediante zócalos de mampostería de piedra pequeña y mediana trabada con barro, con alzados de adobe y cubiertas de láguena. Bloques de piedra o sillares originarios del teatro se insertan en las esquinas, umbrales y jambas, reforzando la estructura. Los pavimentos son de arcilla rojiza apelmazada con una potencia de entre 3 y 6 $\mathrm{cm}$. Entre las unidades domésticas discurren callejones acodados y de trazado irregular, pavimentados con una base de tierra compactada sobre un nivel de gravillas de entre 4 y $7 \mathrm{~cm}$. Los contextos cerámicos asociados son muy similares en las distintas unidades revisadas, conformando un corpus material bien caracterizado en relación con la función de un barrio portuario del momento. Predominan las cerámicas de mesa africanas, en sus formas Hayes 91, 99, 80b/99 y 104, junto a los envases anfóricos Keay XXVI -spatheia-, XXXII, LIII, y LXI o LXII, por citar solo los más frecuentes. A los tipos citados, se añaden, en alguno de los contextos, los ejemplares más tardíos Hayes 105, 101, 107 y 109, propios de las primeras décadas del s. viI (Ramallo et al., 1996). Así sucede en el relleno de una fosa de expolio -uE 5301- con abundante material de distinto tipo entre los que destacan la cerámica de mesa Hayes 91, 93, 58, 90, 106, 105, 99, 109, 103, 61, 63, 91, 80b/99, 99 -varios-, 105, 109, 61, 80b/99, 99, 108, 105, las ánforas Keay XXXII, LXI, XXVI -varios-, LIII -varios-, LIV -varios-, LXII, XXV, XXXII, LXI, XXVI, LIII, LXII, LXI, junto a cerámica de cocina tosca local. Significativo es también el relleno de un pozo circular, excavado en el patio triangular de la Unidad Doméstica A, caracterizado por la presencia de las cerámicas africanas de mesa Hayes 80b/99, 91c, 104C, 105, junto a cerámicas toscas de cocina de producción local y ánforas Keay LIII, xxV y LXII. Gran parte de este repertorio aparece también aplastado contra el pavimento de las estancias en el estrato de incendio que señala el momento final de este barrio de época bizantina.

Otros basureros similares se hallan excavados en la mitad oriental de la ciudad, entre las ruinas de las construcciones de época altoimperial y quizás asociados a estructuras de carácter endeble cuya impronta en el registro arqueológico es muy reducida.

\section{Material y metodología}

Se han analizado un total de 2.723 restos óseos del barrio de época bizantina construido sobre las estructuras del teatro, todos de la segunda mitad del s. vi d. C. y localizados en rellenos de unidades estratigráficas negativas a modo de pozos y basureros, emplazados en patios o al exterior de las unidades domésticas, así como en estratos de nivelación o colmatación, sin que se aprecie diferencia del contenido entre unos y otros. A nivel de detalle, se puede especificar que la mayor parte de las UUEE analizadas proceden de la Habitación 4 -nueve unidades-; seis proceden de la Habitación 7, situada sobre la proedria del teatro de la que solo se ha definido con claridad el ángulo meridional; cuatro unidades provienen, respectivamente, de los Espacios 9 y 13, en 


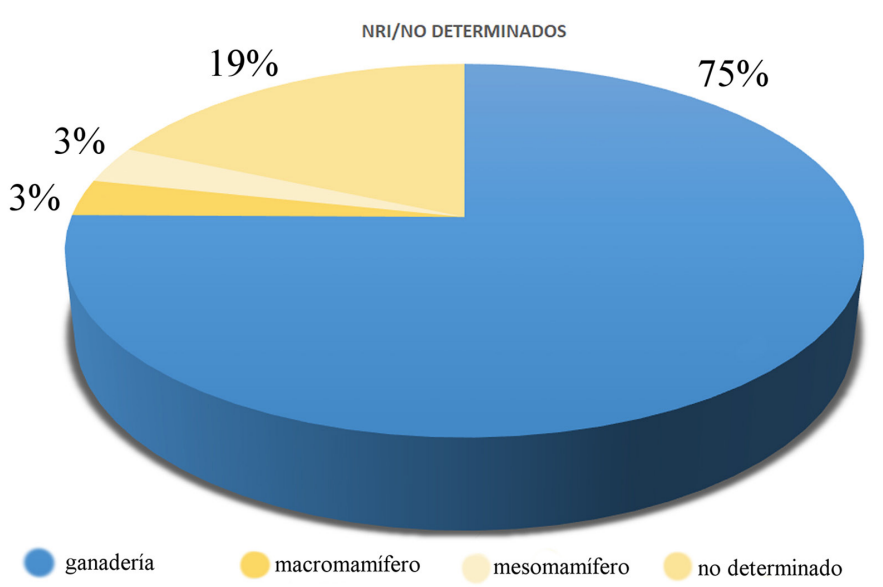

FIG. 2. Porcentajes de los elementos identificados por especies, de los incluidos en los taxones genéricos y de los no determinados.

tanto que el resto corresponden a unidades aisladas en distintos puntos del barrio. La recogida de material faunístico se ha efectuado mediante cribado en seco, habiéndose realizado flotación y el posterior triado solo en algunos contextos cerrados de época islámica, que, en consecuencia, no son analizados aquí.

\subsection{Identificación}

La clasificación taxonómica del conjunto óseo se ha llevado a cabo con la colección de referencia de A. Morales sita en el Laboratorio de Arqueozoología de la Univ. Autónoma de Madrid -LAz-. Puntualmente, esta ha sido complementada con los trabajos de Halstead et al. (2002), Barone (1976), Schmid (1972), Boessneck (1970) y Pohlmeyer (1985) en el caso de la determinación a especie de los atlas y axis de oveja y cabra doméstica.

Debido a la fragmentación del material, se han utilizado agrupaciones genéricas de talla para macro-, meso- y micromamíferos, ya que no siempre fue posible la distinción entre especies con piezas tales como vértebras y costillas, entre otras. En el gráfico de la Fig. 2 se observa el número de restos identificados y los que o bien no pudieron incluirse en ningún taxón, o bien fueron identificados solo a nivel de agrupación genérica de talla.
Por su limitado número, los huesos de aves no han sido incorporados a este estudio por lo que aparecen reflejados en las tablas referidos también a nivel genérico sin más especificaciones (ave).

\subsection{Atribución de edades y sexo}

Para establecer las cohortes de edad se usaron tres métodos. El primero se basa en la erupción dental usando los trabajos de Silver (1970) para caprinos y suidos y Grigson (1982) para bovinos. El segundo método es el desgaste dental (Grant, 1982; Payne, 1973). Es necesario combinar ambas estimaciones ya que la erupción dental con frecuencia depende de factores genéticos y el desgaste dentario del tipo de alimentación. De esta manera, uniendo ambos métodos, nos aseguramos limitar el margen de error (Zeder, 2006). El segundo método de estimación de la edad consistió en contabilizar las epífisis fusionadas y las no fusionadas y analizar los resultados empleando las tablas de fusión ofrecidas por Silver (1970).

Por lo que se refiere a la determinación del sexo, se ha recurrido a elementos como las clavijas óseas de bovinos o los caninos en cerdos para elaborar las agrupaciones, pero debido al limitado número de estos elementos en la muestra no ha podido aportarse información válida para la inferencia de las proporciones sexuales en ninguna cabaña, por lo que los datos no superan el nivel meramente descriptivo. En un futuro, y gracias a las medidas tomadas sobre los restos óseos (Driesch, 1976) se podrá aplicar un análisis biométrico para elaborar las agrupaciones de sexos de manera fiable y realizar un análisis que unifique esta información con la talla de las distintas cabañas.

\subsection{Cuantificación}

El número de restos - NR- se ha calculado para todos los taxones, así como para las categorías de 
restos no identificados, y los identificados solo como macromamíferos, mesomamíferos y micromamíferos ${ }^{2}$. Consideramos que, a pesar de no ser taxones, estas categorías aportan información complementaria acerca de la cabaña ganadera. Junto al NR tenemos estimado el NRI -Número de Restos Identificados sensu Reitz y Wing, 1999- para todas las especies reconocidas.

El número mínimo de individuos - NMI- se calculó teniendo en cuenta el elemento anatómico más abundante considerando la parasagitalidad -izquierdo o derecho- en el caso de los elementos apendiculares (Reitz y Wing, 1999). Además, se utilizó el nivel máximo de agregación (Grayson, 1984), puesto que el NMI se calculó para todo el conjunto de restos de esta fase del yacimiento y no atendiendo a unidades menores como las estratigráficas. De esta manera se simplificó la tarea sin pérdida de información.

Por último, se tomó el peso en seco de cada uno de los taxones para poder complementar la estadística y tener más datos comparables entre especies (Reitz y Wing, 1999: 180).

\subsection{Registro}

La gestión de todos los datos se ha realizado en una base de datos digital -Excel- y siguiendo el método de Davis (1992) con modificaciones que no afectan al análisis. Entre estas destacamos la inclusión del atlas y el axis para la determinación de la especie en caprinos (Pohlmeyer, 1985).

\section{Resultados}

El análisis faunístico confirma la importancia de los animales domésticos -caprinos, bovinos y, en menor medida, los suidos-, que suponen más del $97 \%$ del total de la muestra. Dentro de estas cabañas

2 Estas categorías vienen dadas por el tamaño relativo de los restos, siendo los macromamíferos lo que pueden relacionarse con especies como los équidos; mesomamíferos con los caprinos como ejemplo; y los micromamíferos con los lagomorfos.

(C) Universidad de Salamanca ganaderas, tal y como se refleja en la tabla de la Fig. 3, los porcentajes relativos tanto de NRI como de peso indican que el vacuno es la más representada, con un $22,6 \%$, aunque si consideramos a los caprinos como un solo taxón, estos suponen más de la mitad de la muestra faunística, con casi el 64,5\% de lo identificado taxonómicamente (Fig. 3). En relación al peso observamos más semejanza entre estas dos cabañas, aunque la vaca totaliza casi la mitad del peso total de la cabaña ganadera, frente al más del $37 \%$ de los caprinos. Esto puede deberse a una conservación diferencial de los restos, ya que son más resistentes los del bovino. Por ello, aunque los restos de estos depósitos reflejan en realidad lo consumido y no lo existente en la zona, parece que la cabaña ganadera estuvo dominada por los caprinos.

El siguiente taxón en importancia es el cerdo. Tiene un porcentaje de apenas un 10\%, lo que está en la línea de trabajos para época tardorromana y visigoda en la Península Ibérica, donde se apunta una disminución de la presencia del porcino (Morales, 1992). Los motivos pueden deberse a cambios operados en el uso del suelo, cambios climáticos o simplemente reflejar una agricultura mixta carente de especialización, donde la cría de porcino se llevaría a cabo individualmente en cada uno de los hogares, y no tanto a nivel de piaras (Vigil-Escalera et al., 2014). Un yacimiento de época visigoda próximo a Cartagena, como es Begastri (Morales y Roselló, 2002-2004; Nicolás, 2002-2004), presenta un porcentaje de cerdos idéntico al nuestro -10\%-, lo que afianzaría nuestra hipótesis.

Para concluir con las cabañas ganaderas, destaca lo exiguo de la presencia de equino -solo caballos- en la muestra, con un 3,1\% sobre el total. Ello contrasta con otros yacimientos de la misma época, como ocurre en el yacimiento de Gózquez (Vigil-Escalera et al., 2014), aunque coincide con otros casos como el ya mencionado Begastri, el yacimiento de Zornoztegi en el País Vasco (Grau, 2009) o el Tolmo de Minateda en Albacete (García García, 2016). La escasez de restos de équidos puede responder a una ordenación del tratamiento de basuras, donde esta cabaña, por el hecho de no ser objeto regular de consumo, acabaría preferentemente depositada 


\begin{tabular}{|c|c|c|c|c|c|c|}
\hline Especies & NRI & $\%$ & PESO & $\%$ & NMI & $\%$ \\
\hline Oveja Ovis aries & 240 & 12,2 & 2705 & 10,2 & 12 & 16,9 \\
\hline Cabra Capra hircus & 336 & 17 & 3757 & 14 & 15 & 21,13 \\
\hline Caprino Ovis/Capra & 696 & 35,2 & 3523 & 13,2 & 20 & 28,17 \\
\hline$(\mathrm{O}+\mathrm{C}+\mathrm{O} / \mathrm{C})$ & $(1272)$ & $(64,4)$ & $(9985)$ & $(37,4)$ & $(47)$ & $(66,2)$ \\
\hline Équidos Equus sp. & 61 & 3,1 & 2315 & 8,6 & 4 & 5,63 \\
\hline Bóvidos Bos taurus & 445 & 22,6 & 12280 & 45,8 & 10 & 14,08 \\
\hline Suidos Sus sp. & 196 & 9,9 & 2205 & 8,2 & 10 & 14,08 \\
\hline \begin{tabular}{|l} 
Ganadería \\
\end{tabular} & 1974 & 100 & 16800 & 100 & 71 & 100 \\
\hline Perro Canis familiaris & 8 & & 112 & & & \\
\hline \begin{tabular}{|l|} 
Gato Felis catus \\
\end{tabular} & 1 & & 5 & & & \\
\hline \begin{tabular}{|l} 
Ciervo Cervus elaphus \\
\end{tabular} & 32 & & 605 & & & \\
\hline Conejo Oryctolagus cuniculus & 6 & & 10 & & & \\
\hline Liebre Lepus ganatensis & 8 & & 15 & & & \\
\hline Total & 55 & & 747 & & & \\
\hline Macromamífero & 83 & & 1330 & & & \\
\hline \begin{tabular}{|l|} 
Mesomamífero \\
\end{tabular} & 85 & & 1306 & & & \\
\hline Micromamífero & 1 & & 1 & & & \\
\hline No determinado & 484 & & 1 & & & \\
\hline Total & 653 & & 2637 & & & \\
\hline Ave & 40 & & & & & \\
\hline Pez & 1 & & 1 & & & \\
\hline Total analizado & 2723 & & & & & \\
\hline
\end{tabular}

dental (Fig. 5) se observa como en su mayoría las ovejas se sacrificaron en edad subadulta o adulta mientras que en las cabras las cohortes sacrificadas preferencialmente lo fueron en edad juvenil o subadulta. Estos datos reflejan un patrón de explotación mixto, donde se aprovecharían los productos secundarios como la lana y la leche, y posteriormente se consumiría la carne del animal. Un dato que corrobora este consumo de carne es la frecuencia de las partes anatómicas encontradas. Así, constatamos que las porciones cárnicas más apreciadas suponen un $20,5 \%$, cuartos delanteros, y un $21 \%$, patas traseras, del total contabilizado, res-

en muladares, depósitos pendientes de constatar en Cartagena.

Aun teniendo en cuenta que a nosotros solo nos alcanza una fracción del total originalmente depositado y que, sobre todo, hablamos de restos de consumo y no de animales vivos, podemos avanzar algunas inferencias en torno a la cría, el uso y el consumo de las cabañas ganaderas recuperadas en estos depósitos.

\subsection{Caprinos}

Atendiendo a la edad de sacrificio evidenciada por la fusión epifisaria (Fig. 4) y por la erupción y desgaste pectivamente (Fig. 6). Además, habría que añadir el gran número de costillas indiferenciadas a nivel de especie. Otro dato es la frecuencia de marcas de

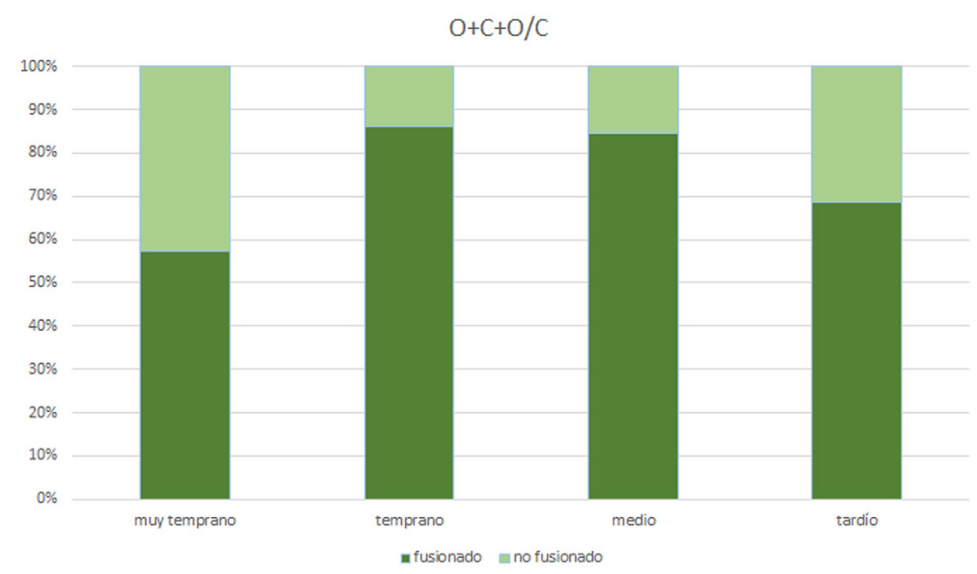

FIG. 4. Fusión epifisaria de caprinos por porcentaje. 
172 J. E. Padilla, A. Morales y S. F. Ramallo / Recursos y hábitos de consumo de la cabaña ganadera en Carthago Spartaria...

10

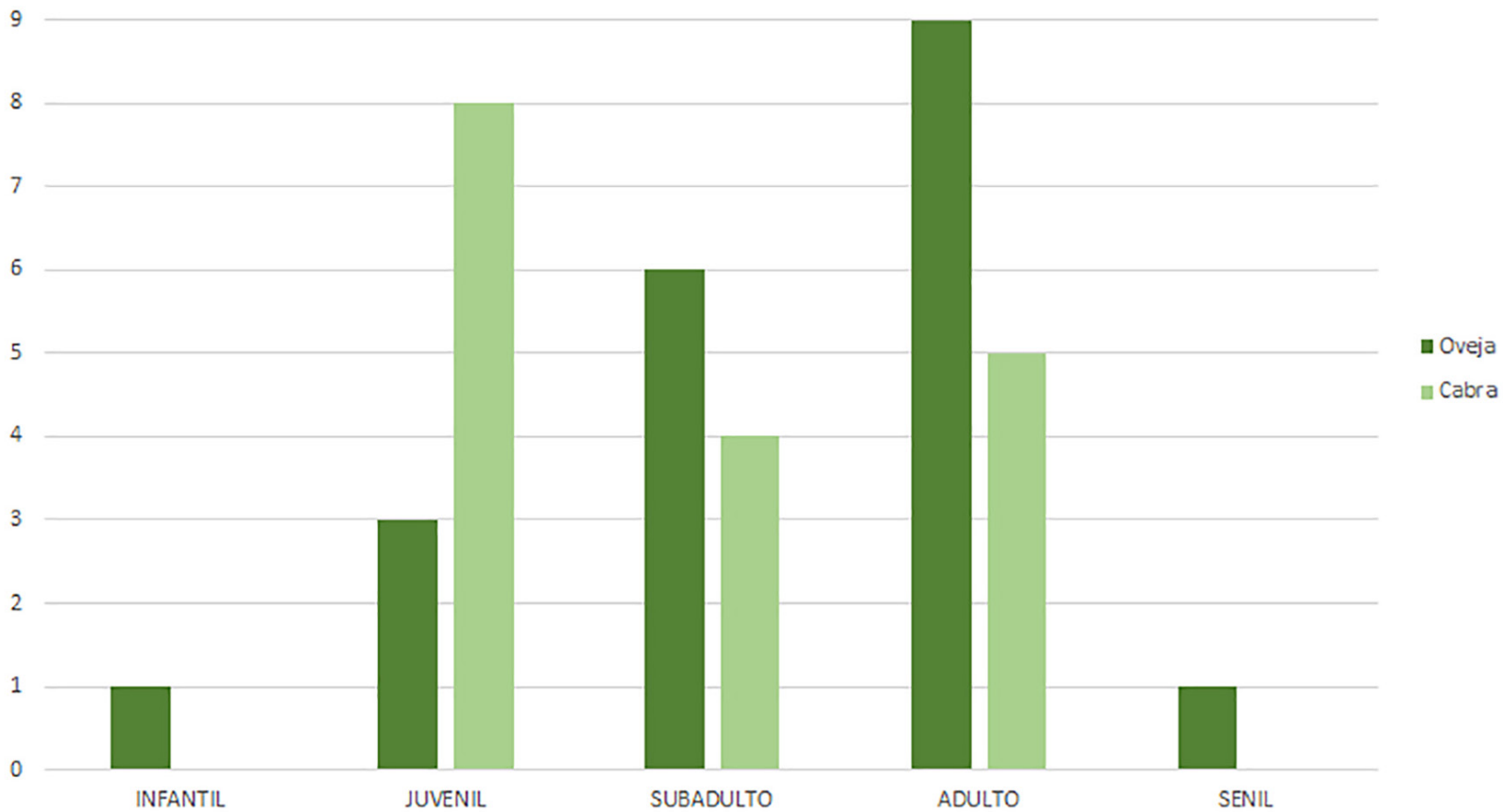

FIG. 5. Cohortes de edad en caprinos por erupción y desgaste dental.

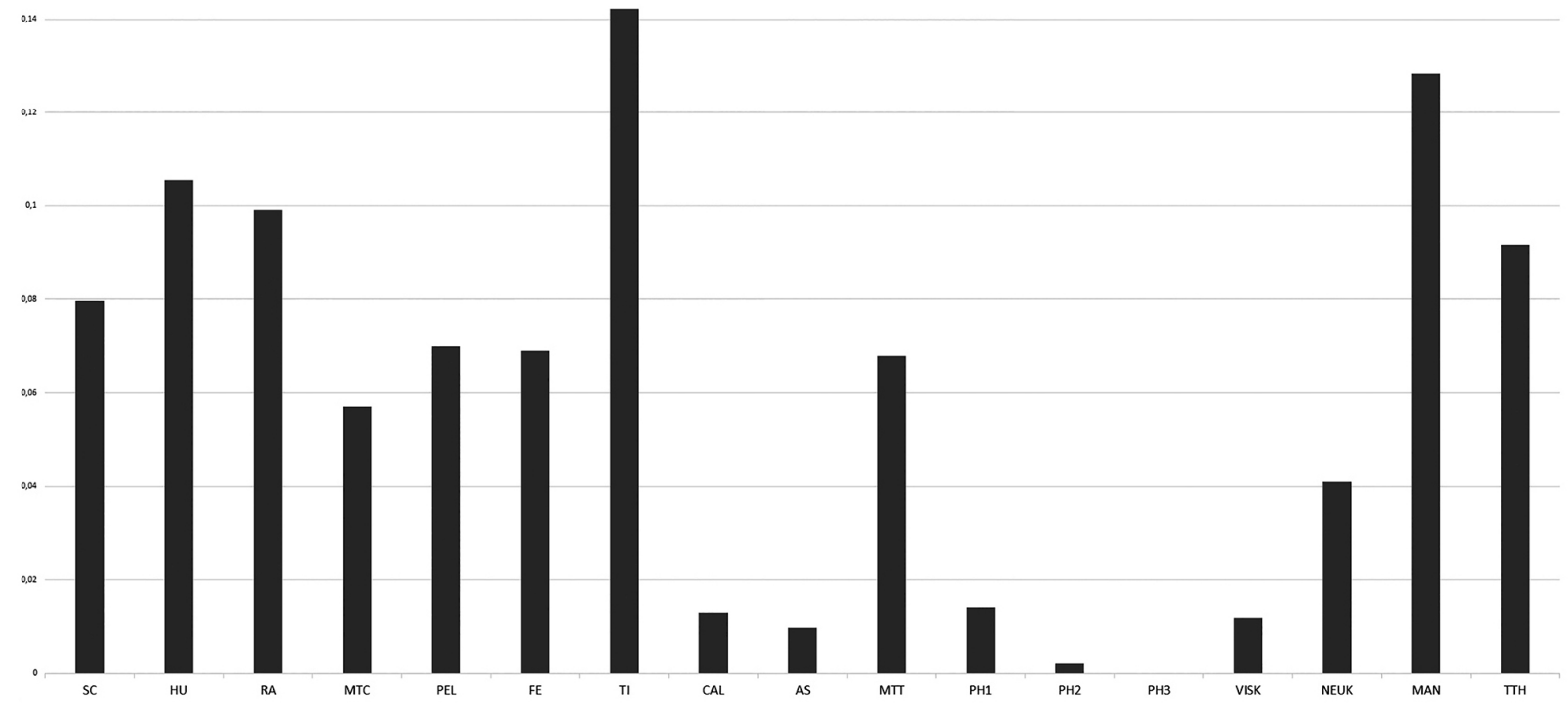

FIG. 6. Frecuencia de partes anatómicas en caprinos: $T T H=$ dientes; $S C=$ escápula; $H U=$ húmero; $R A=$ radio; $M T C=$ metacarpo; $P E L=$ pelvis; $F E=$ fémur $; T I=$ tibia $; C A L=$ calcáneo; $A S=$ astrágalo; $M T T=$ metatarso; $P H 1=1$. falange; $P H 2=2 .{ }^{a}$ falange; $P H 3=3 .{ }^{a}$ falange $;$ VISK = viscerocráneo NEUK = neurocráneo $;$ MAN = mandíbula . 
corte sobre determinados huesos claves como el húmero y el fémur que apuntan a su desarticulación y descarnado.

Otra cohorte bien definida la forman los animales que fueron sacrificados a edad temprana, por debajo del año. Atendiendo al NRI estas cohortes no superan el $6 \%$, pero evidencian un consumo de corderos lechales. Es posible que este porcentaje sea, de hecho, una infraestimación de la situación original ya que, debido a la débil entidad ósea de los elementos esqueléticos en estas edades, el registro puede incorporar un sesgo de recuperación parcial, al igual que con la fauna de pequeñas dimensiones.

Un dato que se desprende del porcentaje de partes anatómicas es el tipo de carnicería, el grado de fragmentación y la eficacia en la metodología de recogida en la excavación arqueológica. El elevado número de piezas dentales, mandíbulas y elementos craneales indica una carnicería primaria repartida por toda la urbe, posiblemente asociada con cada una de las viviendas. Por otro lado, el elevado porcentaje de dientes aislados puede deberse a su acentuada mineralización, que los hace más resistentes y nunca aptos para el carrońeo, o, por el contrario, reflejar un método insuficiente de recogida en las campañas de excavación que vendría a unirse a un alto grado de fragmentación. En este caso, consideramos que es esta última opción la más probable, ya que pocos huesos muestran marcas de mordeduras, roídos o digestión, a lo que vendría a unirse la práctica ausencia de incisivos. Se trata de otro factor que apunta a la ausencia de flotación del sedimento recuperado en la excavación (Grau, 2014: 97-108), algo habitual en las excavaciones de época romana y medieval (Grau y García-García, 2018: 353).

El último aspecto relativo al aprovechamiento de las reses se refiere a la piel, el cual se constata por las marcas recurrentes de incisiones en algunos metapodios (Lloveras et al., 2017; Reitz, 1999: 242-244) y la ausencia de terceras falanges, que debido a su tamaño no necesitan de una recogida especial tipo criba o flotado, lo que apunta a un proceso de desollado.

\subsection{Bovinos}

La edad de sacrificio, observada a través de la fusión epifisaria, varía con respecto a los caprinos, ya que aquí se aprecia una ligera disminución de la edad, siendo en su mayoría los recuperados individuos subadultos (Fig. 7). Este patrón de sacrificio, junto a las partes anatómicas encontradas (Fig. 8), refleja un aprovechamiento preferente de la carne siendo los productos secundarios, leche y estiércol, elementos adicionales en este caso. La presencia de falanges con notables exostosis $-23 \%$ del total- indica que los adultos de esta cabaña se emplearon en tareas agrícolas como fuerza tractora o en el transporte de mercancías, lo que indirectamente refuerza también la hipótesis del aprovechamiento de la leche y el estiércol en los animales, que solo al final de su vida útil serían sacrificados (De Cupere, 2000).

El consumo de la carne, tras amortizar al animal, al igual que ocurre en los caprinos, evidencia un patrón mixto de aprovechamiento de las cabañas

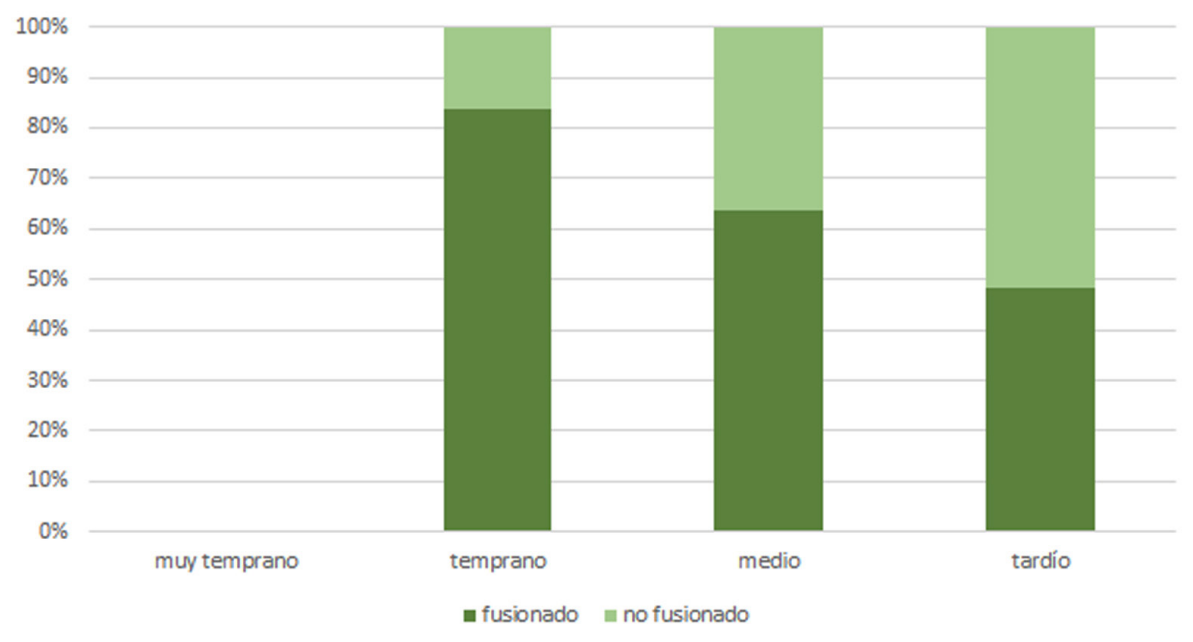

FIG. 7. Fusión epifisaria de vacas por porcentaje. 
0,16

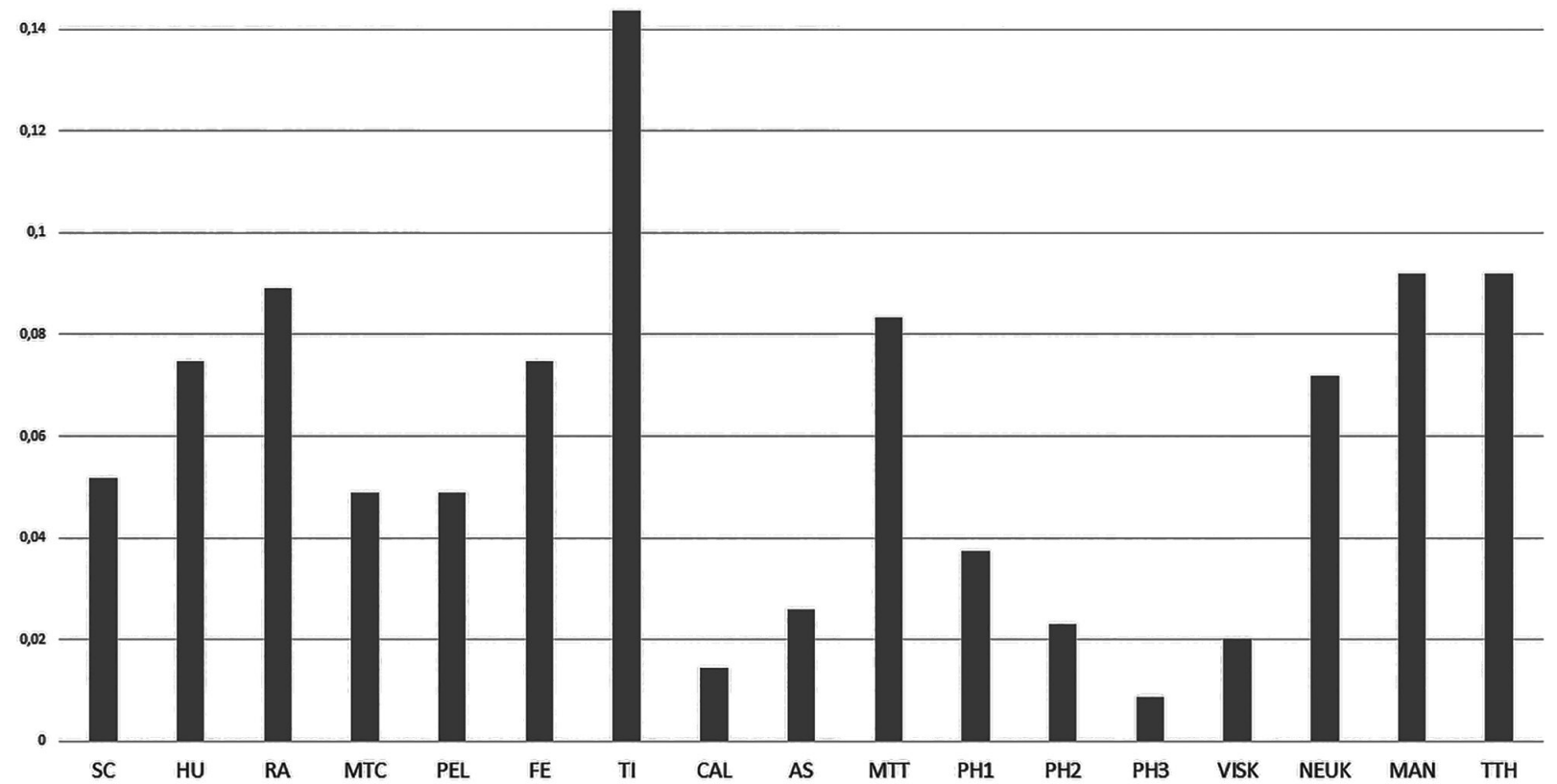

FIG. 8. Frecuencia de partes anatómicas en vaca.

donde, de nuevo en el vacuno, el consumo cárnico supondría unos porcentajes del $20 \%$ tanto para los cuartos delanteros como los traseros. Aunque en los caprinos teníamos "carne de óptima calidad" -animales sacrificados jóvenes-, en el caso del vacuno, al no constatarse individuos por debajo de los 12 meses y sí preferentemente subadultos, lo que parece indicar es que el patrón de explotación cárnica apuntaba a optimizar el rendimiento máximo de la res, esto es, al concluir su período de crecimiento logístico -rápido-.

\subsection{Suidos}

Es obvio que el uso de esta especie es únicamente de consumo cárnico. La edad de sacrificio se centra en subadultos (Fig. 9), cuando esta especie alcanza su óptimo máximo para el consumo. Por ello, como en el vacuno, parece clara la estrategia de optimización del rendimiento y no tanto la calidad de la carne.

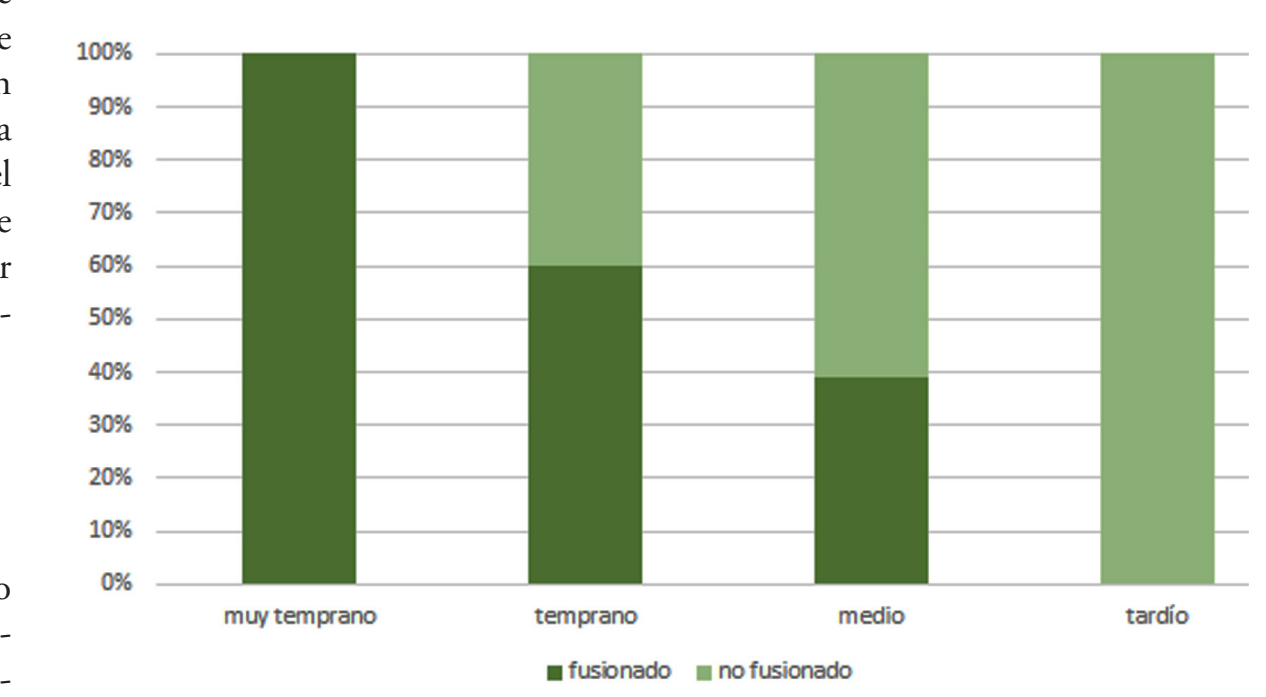

FIG. 9. Fusión epifisaria de cerdos por porcentajes. 


\section{4. Équidos}

La comparación de los 46 restos de équidos con la colección de referencia nos permitió identificar a cuatro de ellos como burros y el resto como caballos. Todos los elementos óseos aparecen con sus epífisis fusionadas, lo que indica ejemplares de edad adulta e incluso senil. Este dato apunta a un patrón de aprovechamiento en tareas agrícolas, al igual que parece haber sido el caso de los bovinos. Dos elementos, un fémur y un húmero, aparecen con marcas de descuartizado y descarnado, lo que indica un aprovechamiento de la carne para el consumo. Es cierto que solo son 2 restos entre 46, lo que señala un caso eventual y esporádico de hipofagia, la cual, en ausencia de información complementaria, se nos antoja difícil decidir si refleja preferencias alimentarias o fue quizás motivado por una carestía puntual de ciertos productos cárnicos de uso más común.

\subsection{Fauna cinegética}

Con respecto a la fauna cinegética, remarcar aquí el dominio del ciervo que supone casi el 60\% del total de este conjunto. Este dato puede resultar equívoco por la conservación y recuperación diferencial de sus restos, lo que puede infravalorar el número real de los lepóridos con respecto al ungulado debido a su menor tamaño. Además, autores como García-Blanco y Vila (2006) señalan que estructuras negativas como hoyos o silos pudieran actuar como trampas naturales para pequeños roedores y lagomorfos. La identificación de marcas de corte sobre dos elementos óseos de lepóridos permite valorar, al menos, algunos de estos taxones como fauna consumida y no intrusiva. Pese a todo ello parece adecuado señalar que en las muestras analizadas predominó la caza mayor.

\section{Discusión}

Los patrones muestran un predominio de los caprinos, con casi dos tercios del total, seguido del bovino. Si atendemos al peso de los restos óseos, esta diferencia no es tan acusada, quedando ambos taxones muy igualados. De manera algo más marginal tenemos al ganado porcino, y mucho más alejado, al caballo con una presencia testimonial. Por lo tanto, y pese al aparente predominio de los caprinos, nos encontramos ante una ganadería mixta, donde la mayoría de los animales -a excepción de las cabras y los cerdos-, así como ciertos bovinos, fueron sacrificados en edad plenamente adulta, lo que implica que se aprovecharon tanto sus productos secundarios como su fuerza tractora. El hecho refleja la importancia de las cabañas restantes -vacuno y porcino- frente a las trashumantes al tiempo que habla indirectamente de la importancia de la agricultura en la zona, a pesar de la acusada reducción de asentamientos rurales durante esta fase en el territorio cercano a la ciudad. A tenor de los datos publicados, este patrón ganadero fue predominante en la Península Ibérica entre los ss. v-viI d. C. Ello plantea la posibilidad de que esta "economía de granja" fuera en parte motivada por la desestructuración del mercado romano y la producción ganadera orientada a este, así como por una necesidad que remitía a la diversificación ganadera mediante una producción mixta, a fin de reducir riesgos. No parece que el descenso en la temperatura que se produjo en la primera mitad del s. vi-Pequeña Edad de Hielo de la Antigüedad Tardía (Büntgen et al., 2016) - pueda haber sido suficiente para generar este cambio en la estrategia pecuaria, aunque los datos disponibles continúan siendo limitados, por lo que no parece adecuado pontificar sobre los mismos.

El porcentaje de porcino es muy bajo, en línea con lo sugerido por D. C. Morales (1992), y refuerza la hipótesis de esta autora señalando que los materiales faunísticos de numerosos yacimientos tardoantiguos contradicen los trabajos de autores que, basándose en las limitadas fuentes escritas, defendían un papel mayor para el cerdo (García, 1989; Orlandis, 1988). También trabajos de índole arqueológica, apoyados por el material faunístico (Lewit, 2009: 80), apuntaron esta tesis del predominio del ganado porcino en esos momentos, si bien es cierto que el material base de las inferencias procedía de Inglaterra oriental. Por todo ello, 
consideramos que la presencia del cerdo en época tardoantigua, tanto en Iberia como en Europa, acusará un fuerte componente regionalista -cuando no local- íntimamente ligado a las estrategias agrícolas, la topografía y el clima de cada zona.

La escasa presencia de fauna cinegética puede reflejar, como señalan algunos autores (Grant, 1988), un descenso demográfico, siendo suficiente el aporte alimentario de la cabaña doméstica para el mantenimiento de la población local. En este sentido, la dominancia del venado, que se pone normalmente en relación con la presencia de una élite (Shelley, 2005) vinculando esta caza a actividades lúdicas o de deporte mediante la obtención de trofeos (Fernández y Fuertes, 2007), no respondería aquí a tales condicionantes. En otras palabras, las bajas demografías permitirían el acceso a este recurso a gente de cualquier estrato social. Un segundo elemento que podría sugerir esta presencia de una élite social, pero también un acceso menos limitado de cualquier clase social al recurso cárnico, serían los restos de cabritos, cuyo sacrificio temprano apunta a un aprovechamiento de calidad frente a cantidad. Lo cierto es que ha sido imposible inferir mediante el análisis faunístico diferencias sociales a través de la distribución espacial de los restos óseos. Al estar todo en basureros con un marcado carácter comunitario y asociados a un barrio portuario, este análisis carece de datos para poder ser realizado.

Por otra parte, la ausencia de estudios faunísticos sobre la Cartagena de época romana induce a comparar nuestros resultados con los de otros yacimientos de la Península Ibérica para determinar si estos patrones ganaderos muestran continuidad con los establecidos para este amplio período precedente. Con esta finalidad, se confrontan las frecuencias de NRI de las tres principales especies con yacimientos romanos, seleccionados con la intención de abarcar un amplio marco geográfico, además de cumplir la condición de ser poblaciones con distinta condición jurídica: Lucus Augusti, Lugo (Altuna y Mariezkurrena, 1996); Ituci, Torreparedones (Morena et al., 2012); Lesera, Forcall-Els Ports (Iborra, 2017), y Laccobrida, Monte Molião (Detry y Arruda, 2013). Se observa en ellos un predominio de vacas y cerdos, pero, en ningún caso, los caprinos llegan a ser el principal taxón -e. d. máximo valor del $32 \%$ en Monte Molião-. Vemos claramente como la cabaña de caprinos va ganando importancia llegando a constituir en época tardorromana el taxón más numeroso ¿Se trata de un progresivo aumento de la trashumancia?

Al comparar nuestros datos con otras zonas coetáneas del Mediterráneo se observa que el patrón mantiene bastantes similitudes con el norte de África, aunque en el caso africano con un aumento de la presencia de suidos que alcanzan el 25,5\% en detrimento de la cabaña bovina con poco más del $8,5 \%$. Para el resto de las zonas este patrón se cumple, siendo la variable la relación porcentual de suidos y bovinos (Kroll, 2012: 96). Por lo tanto, el aumento de caprinos parece obedecer a un cambio cultural y económico, y no tanto a condicionantes geográficos o climáticos.

Si enfrentamos nuestros datos a los aportados por las aldeas de Zornoztegi (Grau, 2009), Gósquez (Vigil-Escalera et al., 2014) y La Solana (Estrada y Nadal, 2007) se mantiene la similitud del patrón ganadero, aunque en nuestro caso con mayor presencia de caprinos. La explicación puede ser que, pese a una mayor demografía asociada a una urbe, y con un profundo sustrato romano, se imponga la necesidad de la diversificación mediante una ganadería mixta en pos de, como se ha señalado anteriormente, limitar los riesgos. Además, es reseñable el hecho de que Cartagena capitalizase gran parte del comercio del sE peninsular mediante su puerto marítimo en aquellos momentos, lo cual induciría a pensar en una producción encaminada a dicho comercio. Pese a todo, debemos admitir que los datos disponibles no apoyan esta tesis y sí, en cambio, la de la autosuficiencia de la población local, algo que también podría deducirse del circulante monetario, caracterizado por pequeños divisores acuñados en la ciudad y escasa presencia de los valores mayores (Lechuga y Méndez, 1986).

En cualquier caso, la muestra analizada refrenda la importancia que la ganadería tuvo como actividad económica y en la dieta de la Carthago Spartaria de la segunda mitad del s. vi y primeras décadas 
del s. vir. En cierto modo, su importancia había quedado tradicionalmente postergada a un segundo plano, debido a la ausencia de referencias escritas y también al escaso número de análisis arqueofaunísticos realizados y la limitada representatividad de especies (Portí, 1991). No obstante, el elevado número de pozos y vertederos domésticos con abundante material óseo aún sin estudiar en contextos de los ss. $\mathrm{v}$ al vir excavados en distintos puntos de la ciudad (Egea et al., 2011) completarán sin duda los datos aportados ahora por los contextos del barrio de época bizantina asentado sobre el teatro.

Por otra parte, las especies representadas en el registro arqueológico son características de esta región. No se observan otras que pudieran haber sido introducidas a través del comercio sea por vía marítima o bien desde otros territorios más alejados. En este sentido, hay que contemplar la existencia de un pastoreo de pequeños rebaños de ganado lanar y caprino con un número limitado de cabezas, suficientes para cubrir las necesidades de la población local. Estos rebaños, a los que se unieron otras cabezas de bovino, se beneficiaron del entorno semipantanoso del almarjal, que constreñía la ciudad por el norte, salpicado por matorral herbáceo de carácter halófilo, del sector endorreico del Campo de Cartagena y del reborde del Mar Menor, tierras cuya elevada salinidad aportaba un componente esencial para el desarrollo ganadero.

Los pastizales se debieron extender, además, sobre todo para los rebaños de caprinos, a las elevaciones montañosas que bordean la urbe por el o -Sierra de Pelayo- y al E -Sierra Gorda-. En ambos casos, una vegetación arbustiva -lentiscares- y esteparia, entre algunos retazos de pino carrasco, junto a las suaves condiciones climáticas y los abrevaderos alimentados por los manantiales de los Cabezos de San Juan y Calvario, a Levante, y Atalaya, a Poniente, procuraban las condiciones adecuadas para el pastoreo de estos rebaños.

En cuanto a la ubicación de posibles apriscos y rediles, el registro arqueológico apenas aporta información, ya que, al ser estructuras realizadas en muchos casos con materiales perecederos u ocasionales, su huella es más difícil de identificar. Ya hemos comentado antes el abandono como zona urbanizada de la mitad oriental de la ciudad fortificada de época altoimperial. A partir del s. v, el sector más meridional de este amplio espacio abandonado es ocupado por una necrópolis que progresivamente se va extendiendo de o a E. Ante esta situación, es posible que la otra mitad, separada de la necrópolis por el decumanus que comunicaba la puerta oriental con el área portuaria, pudiera haber acogido espacios de estabulación asociados a construcciones efímeras, aunque no es posible afirmarlo con rotundidad. Por otra parte, también es probable que, dado el carácter desagregado de las unidades domésticas en el nuevo espacio intramuros, existieran establos o recintos cercados entre las viviendas, donde se ubicaría el ganado porcino y equino. La presencia de estos recintos contribuiría a proporcionar una imagen "ruralizada" de la ciudad, muy diferente al aspecto monumental de la urbe de época altoimperial, caracterizada por los grandes complejos públicos.

Por otra parte, fuera de la ciudad y a nivel del territorium, los ss. VI y VII representan una drástica disminución en el número de asentamientos de función agropecuaria frente a las dos centurias anteriores (Murcia, 2011). Esta situación debió provocar que la superficie de cultivo, ya mermada frente a los siglos precedentes, disminuyera considerablemente, extendiéndose amplias zonas de ramoneo y pastoreo en las nuevas tierras baldías. En este sentido, el ager carthaginiensis y, sobre todo, el arco más cercano a la ciudad dispuso de suelos de elevada potencialidad agrológica (Fig. 10), aunque la escasez de recursos hídricos permanentes pudo limitar el desarrollo de los cultivos, estimulando actividades complementarias de carácter ganadero.

Las fuentes escritas de época romana resaltan los recursos mineros, en particular la plata, las salsas derivadas del pescado y el esparto como los más importantes del ager o territorio de Cartagena; nada mencionan en cambio respecto a la ganadería, cuyo peso en la economía de la zona debió ser mayor al que le atribuyen los textos escritos. Este hecho es en gran parte generalizable a otros territorios de Hispania. Hay que esperar a época bajomedieval para 
178 J. E. Padilla, A. Morales y S. F. Ramallo / Recursos y hábitos de consumo de la cabaña ganadera en Carthago Spartaria...

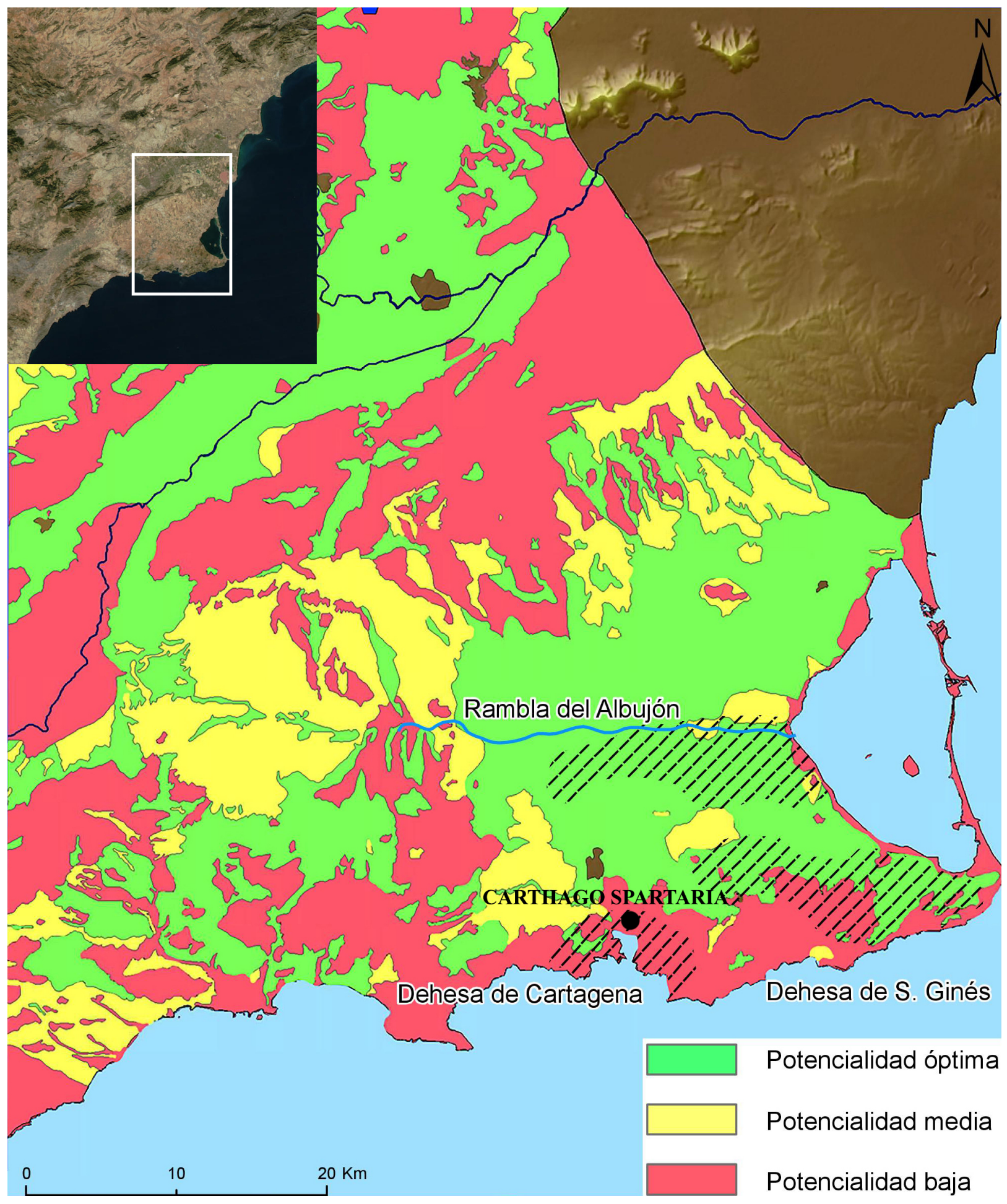

Fig. 10. Mapa de la potencialidad agrícola del suelo: los de alta potencia en verde, los de potencia media en amarillo y los de poca potencia en rojo; en trama rayada dehesas y pastos durante la Baja Edad Media (según Martínez Carrillo, 1986: 161 modificado). 
encontrar documentación exhaustiva sobre el papel desempeñado por la ganadería como actividad y recurso económico de Cartagena, cuyo campo constituyó uno de los extremos de invernada en la cañada de Cuenca, una de las cuatro principales del Reino de Castilla ${ }^{3}$. La afluencia de ganados desde Cuenca, Teruel y Valencia fue continua y en aumento a lo largo de los ss. XIV, Xv y XVI; desde el s. XIV, unas 50.000 cabezas de ganado, por término medio, se dirigían a invernar en el campo de Cartagena (Martínez Carrillo, 1986: 164). Los documentos mencionan la existencia de las dehesas de Campo Nubla, al oeste, la de Cartagena -o dehesa concejil-, arco que se extendía una legua alrededor de la ciudad, y las de Escombreras y Rincón de San Ginés, así como de amplios pastizales paralelos al curso de la rambla del Albujón, cauce de caudal irregular que recogía, a su vez, las avenidas de otros menores, para evacuar en el Mar Menor (Martínez Carrillo, 1986: 161). La razón de esta ubicación estriba en la fácil posibilidad de obtener agua, bien mediante pozos, o bien por las avenidas torrenciales de las ramblas que los bordean o atraviesan. En este sentido, se ha podido constatar cómo en muchos de los establecimientos romanos que salpican estos espacios se construyen sistemas de aprovisionamiento hídrico mediante grandes balsas o cisternas que, situadas en los extremos de estos cauces, servían para recoger y acopiar el agua de las avenidas torrenciales que de forma ocasional se producirían en las estaciones más lluviosas (García Blánquez, 2014). Dadas estas circunstancias, no es aventurado sospechar que parte de estos pastizales serían ya utilizados en época tardorromana e, incluso, formaran parte del bosque y pastos comunales - silvae et compascua- gestionados directamente por la colonia. No obstante, la evolución de estos espacios y su regulación jurídica es desconocida, más aún a partir del s. III y sobre todo a finales de la Antigüedad.

3 Montojo, V. (1991): Cartagena a principios de la Edad Moderna (1500-1580): comportamientos económicos y sociales de la evolución de una ciudad portuaria del sudeste español y su comarca. Tesis doctoral presentada en 1991 en la Univ. de Murcia. Recuperada de http://hdl.handle. net/10803/96087; cf. p. 254.

4 Cf. también Montojo, op. cit. n. 3, fig. 2.

\section{Conclusión}

Los resultados arqueofaunísticos presentados en este trabajo completan, desde una perspectiva diferente y necesaria, los ingentes datos ofrecidos por este importante yacimiento arqueológico. En este marco, se ofrece por primera vez una documentación contextualizada y estadísticamente amplia de las especies que conformaban la cabaña pecuaria que constituía la base alimentaria en una ciudad hispana en la Tardoantigüedad, aunque su imagen urbana distara ya mucho de la monumental Carthago Nova de los ss. I y iI d. C.

A pesar de ser un primer análisis paleobiológico sobre un significativo depósito de la ciudad, abierto a otros futuros registros, el período estudiado se configura como un momento clave en la historia de la ganadería hispana, en el que se producen cambios sustanciales en los hábitos alimenticios de la población. Estos cambios se traducen en nuestro caso en una economía marcada por una ganadería variada en especies, en pos de reducir las posibles crisis alimentarias y el aprovechamiento máximo del animal tanto en productos secundarios como en su óptimo cárnico. Además, esta cabaña ganadera está orientada al autoconsumo, girando en torno a los espacios abiertos de las diferentes viviendas, lo que se aleja de la imagen comercial que se tenía en el mundo romano. A este respecto, se aproxima una definición más precisa de la dieta de los habitantes de la ciudad en este período, incidiendo en el peso de la ganadería dentro de sus patrones económicos. En este sentido, el análisis brinda una base más segura para interpretar con mayor rigor los cambios que se producen en el repertorio vascular del momento, en relación con dietas y hábitos alimentarios (Arthur, 2007). Estos cambios se manifiestan en el predominio casi absoluto de ollas y cazuelas de amplio diámetro que, en el caso de Cartagena, dominan los contextos de los ss. VI y viI (Ramallo et al., 1996).

Desde una perspectiva social, los resultados sobre el material analizado reflejan un estadio intermedio en los hábitos de consumo y aprovechamiento de la cabaña ganadera entre una ciudad gobernada por una élite local enriquecida, con sus 
esclavos y libertos, y la sociedad con instituciones de carácter teocrático y más igualitaria que representa el mundo islámico, condicionada por las estrictas normas impuestas por el Corán.

En cualquier caso, conviene resaltar que los datos aportados por este estudio complementan la restitución paleoambiental de Cartagena y su entorno en lo que respecta al primer milenio (Torres et al., 2018), al igual que los datos hasta ahora disponibles sobre la economía y las dinámicas sociales no solo de Cartagena, en sus distintos períodos históricos, sino también de otras zonas del territorium de la ciudad. El reto en un futuro inmediato será seguir contrastando estos datos con otros de diferentes zonas o épocas, así como ampliar y complementar con otro tipo de registros paleoecológicos en dichas zonas.

\section{Bibliografía}

Altuna, J. y Mariezkurrena, K. (1996): "Estudio arqueológico de los restos óseos hallados en las excavaciones romanas de Lugo". En Rodríguez, A. (coord.): Lvcvs Avgvsti I. El amanecer de una ciudad. A Coruña: Fundac. Pedro Barrié de la Maza, pp. 55-106.

Arthur, P. (1994): Il complesso Archeologico di Carminiello ai Mannesi, Napoli (Scavi 1983-1984). Collana del Dipartimento, 7. Lecce: Univ. di Lecce, Dipartimento di Beni Culturali, Settore StoricoArcheologico.

Arthur, P. (2007): "Pots and boundaries. On cultural and economic areas between Late Antiquity and the Early Middle Ages". En Bonifay, M. y Tréglia, J. Ch. (eds.): Late Roman Coarse Wares, Cooking Wares and Amphorae in the Mediterranean. Archaeology and Archaeometry (LRCW 2). BAR Intern Ser. 1662. Oxford: Hadrian Books Ltd.

Barone, R. (1976): Anatomie comparée des mammiferes domestiques. Tome I: Ostéologie. Paris: Vigot Frères.

Boessneck, J. (1970): "Osteological differences between sheep (Ovis aries L.) and goat (Capra hircus L.)". En Brothwel, D. R. e Higgs, E. S. (eds.): Science in archaeology. London: Thames \& Hudson, pp. 331-358.

Büntgen, U.; Myglan, V.; Ljungqvist, F. C.; McCormick, M.; Di Cosmo, N.; Sigl, M.; Jungclaus, J.; Wagner, S.; Krusic, P.; Esper, J.; Kaplan, J.;
De Vaan, M.; Luterbacher, J.; Wacker, L.; TeGEL, W. y Kirdyanov, A. (2016): "Cooling and societal change during the Late Antique Little Ice Age from 536 to around 660 AD", Nature Geoscience, 9, pp. 231-236. doi: 10.1038/ngeo2652.

Burke, A. (2001): "Animal Bones". En Stirling, L. M.; Mattingly, D. J. y Ben Lazreg, N. (eds.): Leptiminus (Lamta). Report 2. The East Baths, Cemeties, Kilns, Venus Mosaics, Site Museum and Other Studies. Journal of Roman Archaeology Suppl. Ser., 41. Portsmouth, pp. 442-456.

Crabtree, P. J. (2010): “Agricultural innovation and socio-economic change in early medieval Europe: evidence from Britain and France", World Archaeology, 42 (1), 122-136.

DAVIS, S. (1992): "A rapid method for recording information about mammal bones from archaeological sites", Ancient Monuments Laboratory Report, 19, pp. 1-16.

Detry, C. y Arruda, A. M. (2013): “A fauna da Idade do Ferro e época romana de Monte Molião (Lagos, Algarve): continuidades e rupturas na dieta alimentar", Revista Portuguesa de Arqueologia, 15, pp. 215-227.

Egea, A.; Ruiz, E. y Vizcaíno, J. (2011): "Carthago Nova”. En Remolá, J. A. y Acero, J. (eds.): La gestión de los residuos urbanos en Hispania. Anejos de Archivo Español de Arqueología, LX. Mérida, pp. 281-296.

Estrada, A. y NADAL, J. (2007): "La Solana, estudi zooarqueològic del jaciment". En Barrasetas, M. E. (ed.): La Solana. Memòria de l'excavació arqueològica al jaciment. Barcelona: Generalitat de Catalunya, pp. 1-26.

Fernández, C. y Fuertes, N. (2007): "La romanización del noroeste de la Península Ibérica y las modificaciones en la presencia, uso y consumo de los mamíferos". En Jorge, S. O.; Bettencourt, A. y Figueiral, I. (eds.): A concepção das paisagense e dos espaços na Arqueologia da Peninsula Ibérica. Actas IV Congresso de Arqueologia Peninsular. Promontoria Monográfica, 8. Faro: Centro de Estudos de Patrimonio-Univ. do Algarve, pp. 207-217.

García, L. A. (1989): Historia de la España visigoda. Madrid: Cátedra.

García Blánquez, L. A. (2014): “Aprovisionamiento hidráulico romano en medios semiáridos. El caso del ager carthaginensis". En López BALLesTA, J. M. (ed.): Uso y gestión de recursos naturales en medios semiáridos del ámbito mediterráneo. Mazarrón: Univ. Popular, pp. 246-272.

García García, M. (2016): "Primeros resultados del estudio arqueozoológico del Tolmo de Minateda 
(Hellín, Albacete): caracterización preliminar de la muestra derivada del basurero de época visigoda del Reguerón”. En Gamo, B. y SANZ, R. (coords.): Actas I Reunión Cientifica de Arqueología de Albacete. Albacete: Instituto de Estudios Albacentenses Don Juan Manuel, pp. 637-658.

García-Blanco, V. y Vila, S. (2006): "Restos animales y vegetales del yacimiento visigodo de Prado de los Galápagos, interpretación ambiental", Zona Arqueológica, 8 (3), pp. 962-972.

Grant, A. (1982): "The use of tooth wear as a guide to the ageing of domestic ungulates". En WiLson, B.; Grigson, C. y Payne, S. (eds.): Ageing and Sexing Animal Bones from Archaeological sites. BAR British Series, 109. Oxford: Archaeopress, pp. 31-108.

Grant, A. (1988): "Animal resources". En Astill, G. y Grant, A. (eds.): The countryside of medieval England. Oxford: Blackwell, pp. 149-187.

Grau, I. (2009): "Ganadería en la Alta Edad Media. Estudio comparativo de los yacimientos alaveses de Zornoztegi, Zaballa y Salvatierra-Agurain”, Munibe, 60, pp. 253-280.

Grau, I. (2014): "Waste management at early medieval rural sites in northern Spain: Taphonomic issues for interpreting faunal remains", Quaternary International, 330, pp. 97-108. doi: 10.1016/j. quaint.2013.12.016.

Grau, I. y García-García, M. (2018): "Zooarqueología y Edad Media en la Península Ibérica”. En QuiRós, J. A. (ed.): Treinta años de Arqueología Medieval en España. Oxford: Archaeopres Publishing Ltd.

Grayson, D. (1984): Quantitative zooarchaeology. Orlando: Academic Press.

Grigson, C. (1982): "Sex and age determination of some bones and teeth of domestic cattle: review of the literature". En Wilson, B.; Grigson, C. y Payne, S. (eds.): Ageing and Sexing Animal Bones from Archaeological sites. BAR British Series, 109. Oxford: Archaeopress, pp. 7-23.

Halstead, P.; Collins, P. e Isaakidou, V. (2002): "Sorting the sheep from the goats: morphological distinctions between the mandibles and mandibular teeth of adult Ovis and Capra", Journal of Archaeological Science, 29 (5), pp. 545-553.

IBORRA, M. P. (2017): "Arqueozoología de época romana en el País Valenciano”, Archaeofauna, 26, pp. 23-38.

Kroll, H. (2010): Tiere im Byzantinischen Reich. Archäozoologische Forschungen im Überblick. Monographien des Römisch-Germanischen Zentralmuseums, 87. Berlin: Leibniz Gemeinschaft.
Kroll, H. (2012): "Animals in the Byzantine Empire: An Overview of the Archaeozoological Evidence", Archeologia Medievale, 39, pp. 93-121.

Lechuga, M. y Méndez, R. (1986): "Numismática bizantina de Cartagena". En MAs, J. (dir.): Historia de Cartagena. Murcia, vol. v, pp. 71-78.

LewIt, T. (2009): "Pigs, presses and pastoralism: farming in the fifth to sixth centuries AD", Early Medieval Europe, 17 (1), pp. 77-91.

Lloveras, L.; Thomas, R.; García, A.; Florensa, F.; Segura, S.; Medina, E.; Orri, E. y Nadal, J. (2017): "Evidence of Cat (Felis catus) Fur Exploitation in Medieval Iberia", International Journal of Osteoarchaeology, 27, pp. 867-879. doi: 10.1002/ oa.2600.

Martínez, M. Ll. (1986): "Población y término de Cartagena en la Baja Edad Media". En I Concurso de Historia de Cartagena "Federico Casal". Cartagena: Ayto. de Cartagena, pp. 143-206.

McCormick, M. (2001): Origins of the European Economy: Communications and Commerce AD. 300-900. Cambridge: CuP.

McCormick, M. (2003): "Complexity, chronology and context in the early medieval economy", Early $\mathrm{Me}$ dieval Europe, 12 (3), pp. 307-323.

Morales, D. C. (1992): "Pig husbandry in Visigoth Iberia: fact and theory", Archeofauna: International Journal of Archaeozoology, 1, pp. 147-155.

Morales, A. y Roselló, E. (2002-2004): "Los restos animales del yacimiento de Begastri (Cehegín, Murcia). Análisis de la fauna de las siete primeras campañas (1980-1986)", Alqvipir. Revista de Historia, 12, pp. 111-154.

Morena, J. A.; Moreno, A. y Martínez, R. M. (2012): El macellum de la Colonia Ituci Virtus Iulia (Torreparedones. Baena, Córdoba). Salsum, 3. Monografías del Museo Histórico Municipal de Baena. Baena.

Murcia, A. J. (2010): "El poblamiento romano en el Campo de Cartagena (siglos III a. C. - vII d. C.)". En Noguera, J. M. (ed.): Poblamiento rural romano en el sureste de Hispania: 15 años después. Murcia: Editum, pp. 131-155.

Nicolás, E. (2002-2004): "Los restos animales de Begastri (Campaña 2000)", Alqvipir. Revista de Historia, 12 , pp. 155-187.

Noвis, G. (1999): “Die Tierreste von Karthago". En Raков, F. (ed.): Die Deutschen Ausgrabugen in Karthago 3. Mainz: Phillip von Zabern, pp. 574-631.

OrLandis, J. (1988): Historia del reino visigodo español. Madrid: Rialp. 
182 J. E. Padilla, A. Morales y S. F. Ramallo / Recursos y hábitos de consumo de la cabaña ganadera en Carthago Spartaria...

Payne, S. (1973): "Kill-off patterns in sheep and goats: the mandibles from Asvan Kale". En Anatolian studies, 23, Ashvan 1968-1972, an interim report, pp. 281-303. doi: 10.2307/3642547.

Peytremann, E. (2003): Archéologie de l'habitat rural dans le nord de la France du VI au XIt siècle. SaintGermain-en-Laye: Association Française d'Archéologie Mérovingienne.

Pohlmeyer, K. (1985): Zur vergleichenden Anatomie von Damtier, Schaf und Ziege. Osteologie und postnatale Osteogenese. Berlin-Hamburgo: Verlag, pp. 16-28.

PorTí, M. (1991): "Estudio de la fauna del depósito tardoantiguo de la calle del Duque 33 de Cartagena", Antigüedad y Cristianismo, 8, pp. 341-353.

Ramallo, S. F.; Ruiz, E. y Berrocal, M. C. (1996): "Contextos cerámicos de los siglos v-VII en Cartagena”, Archivo Español de Arqueología, 69, pp. 135-190.

Ramallo, S. F.; Ruiz, E.; Murcia, A. J. y Guillermo Martínez, M. (2013): “Aproximación a las fases de ocupación de Cartagena a partir del registro arqueológico obtenido en las intervenciones del teatro romano: breve síntesis de su evolución urbana", Anales de Prehistoria y Arqueología, 29, pp. 23-56.

Reitz, E. y Wing, E. (1999): Zooarchaeology. Cambridge: Cambridge University Press.

Schmid, E. (1972): Atlas of animal bones. For prehistorians, archaeologists and Quaternary geologists. London: Elsevier.

Shelley, A. (2005): Dragon Hall, King Street, Norwich: Excavation and Survey of a Late Medieval Merchant's Trading Complex. East Anglian Archaeology, 112. Norfolk: Norfolk and Norwich Heritage Trust.
Silver, I. A. (1970): "The ageing of domestic animals". En Brothwell, D. R. e Higgs, E. S. (eds.): Sciencein archaeology: A survey of progress and research (2. ${ }^{\mathrm{a}}$ ed.). New York: Praeger Publishing, pp. 283-302.

Torres, T.; Ramallo, S.; Sánchez-Palencia, Y.; Ros, M. M.; Ortiz, J. E.; Navarro, F.; Cerezo, F.; Rodríguez-Estrella, T. y Manteca, I. (2018): "Reconstructing human-landscape interactions in the ancient Mediterranean harbour of Cartagena (Spain)", The Holocene, 28 (6), pp. 879-894.

Van Ossel, P. (2010): "De la 'villa' au village: les premices d'une mutation". En Yante, J. M. y Bultot-Verleysen, A.-M. (eds.): Autour du “village'. Établissements humains, finages et communautés rurales entre Seine et Rhin (IV -XIIT siècles). Louvain-la-Neuve: Univ. Catholique de Louvain, pp. 219-236.

Vigil-Escalera, A.; Moreno-García, M.; Peña-ChoCarro, L.; Morales, A.; Llorente, L.; Sabato, D. y Ucchesu, M. (2014): "Productive strategies and consumption patterns in the Early Medieval village of Gózquez (Madrid, Spain)", Quaternary International, 346, pp. 7-19.

Von den Driesch, A. (1976): A guide to measurement of animal bones from archaeological sites. Peabody $\mathrm{Mu}-$ seum Bulletin, 1. Harvard: Harvard University.

Zeder, M. A. (2006): "Reconciling Rates of Long Bone Fusion and Tooth Eruption and Wear in Sheep (Ovis) and Goat (Capra)". En Albarella, U.; Dobney, K. y Rowley-Conwy, P. (eds.): Proceedings $9^{\text {th }}$ Conference of the International Council for Archaeozoology (Durham, 2002). Oxford: Oxbow Books, pp. 87-118. 


\section{ANEXO}

\begin{tabular}{|c|c|c|c|c|c|c|c|c|c|c|c|c|c|c|c|c|c|}
\hline $\begin{array}{c}\text { CABAÑA } \\
\text { GANADERA }\end{array}$ & SC & $\mathrm{HU}$ & RA & MTC & PEL & $\mathrm{FE}$ & TI & CAL & AS & MTT & PH I & $\mathrm{PH} 2$ & $\mathrm{PH}_{3}$ & VISK & NEUK & MAN & TTH \\
\hline Ovis aries & 13 & 22 & 24 & 13 & 19 & 16 & 21 & 5 & 3 & 16 & 5 & 0 & 0 & 4 & 5 & 20 & 24 \\
\hline Capra hircus & 34 & 36 & 27 & 29 & 10 & 23 & 29 & 6 & 6 & 27 & 6 & 0 & 0 & 2 & 1 & 35 & 21 \\
\hline Caprino & 27 & 40 & 41 & 11 & 36 & 25 & 82 & 1 & 0 & 20 & 0 & 2 & 0 & 5 & 32 & 64 & 40 \\
\hline Equus sp. & 0 & 4 & 6 & 10 & 7 & 2 & 8 & 0 & 0 & 1 & 2 & 1 & 4 & 0 & 0 & 1 & 8 \\
\hline Bos taurus & 18 & 26 & 31 & 17 & 17 & 26 & 50 & 5 & 9 & 29 & 13 & 8 & 3 & 7 & 25 & 32 & 32 \\
\hline Sus scrofa & 12 & 19 & 8 & 5 & 6 & 5 & 18 & 0 & 1 & 6 & 0 & 0 & 0 & 9 & 20 & 20 & 15 \\
\hline
\end{tabular}

Desglose anatómico de los diferentes taxones representados de la cabaña ganadera.

\begin{tabular}{|c|c|c|c|c|c|c|c|c|c|c|c|}
\hline & $\begin{array}{l}\text { ANCHURA } \\
\text { PROXIMAL }\end{array}$ & $\begin{array}{c}\text { ANCHURA } \\
\text { MÍN. DIÁFISIS }\end{array}$ & $\begin{array}{c}\text { ANCHURA } \\
\text { DISTAL }\end{array}$ & $\begin{array}{l}\text { LONGITUD } \\
\text { MÁXIMA }\end{array}$ & $\begin{array}{l}\text { ALtURA } \\
\text { MÁXIMA }\end{array}$ & $\begin{array}{l}\text { LONGITUD } \\
\text { MÁXIMA }\end{array}$ & $\begin{array}{l}\text { LONGITUD } \\
\text { DORSAL }\end{array}$ & $\begin{array}{c}\text { GROSOR } \\
\text { PROXIMAL }\end{array}$ & $\begin{array}{l}\text { LONGITUD } \\
\text { MÁX. } \\
\text { PERIFÉRICA } \\
\end{array}$ & $\begin{array}{l}\text { ALtURA } \\
\text { MÍN. } \\
\text { ÍLEON } \\
\end{array}$ & $\begin{array}{l}\text { LONGITUD } \\
\text { ACETABULAR }\end{array}$ \\
\hline F1 & 36,2 & 24,5 & 33,9 & 67,6 & & & & & & & \\
\hline F1 & 35,1 & 21,2 & 30,6 & 64,6 & & & & & & & \\
\hline F2 & 52,3 & 31,3 & 39,1 & 75,8 & & & & & & & \\
\hline F3 & & & & & 25,8 & 34,0 & 30,9 & & & & \\
\hline F3 & & & & & 23,8 & 36,6 & 32,4 & & & & \\
\hline F3 & & & & & 33,0 & 65,2 & 50,1 & & & & \\
\hline F3 & & & & & 29,8 & 37,1 & 33,2 & & & & \\
\hline Húmero & & 29,0 & & & & & & & & & \\
\hline Húmero & & & & & & & & 90,0 & & & \\
\hline Húmero & 61,5 & 25,2 & & & & & & 69,0 & & & \\
\hline Radio & 67,9 & & & & & & & & & & \\
\hline Radio & & 28,2 & 53,5 & & & & & & & & \\
\hline Metacarpo & 38,4 & 24,7 & 35,5 & 167,3 & & & & & & & \\
\hline Metacarpo & 54,8 & 35,6 & 49,8 & 230,1 & & & & & & & \\
\hline Metacarpo & 35,6 & 24,0 & 32,6 & 173,1 & & & & & & & \\
\hline Pelvis & & & & & & & & & & 24,1 & 40,3 \\
\hline Tibia & & & 57,2 & & & & & & & & \\
\hline Tibia & & 36,1 & 63,1 & & & & & & & & \\
\hline Metatarso & 41,8 & 25,1 & 38,3 & 233,5 & & & & & & & \\
\hline
\end{tabular}

Desglose de los datos métricos en los équidos; todas las medidas están expresadas en cm. 
